\title{
O PAPEL DO TUTOR NO PROCESSO DE APRENDIZAGEM DO ALUNO DE EDUCAÇÃO A DISTÂNCIA
}

PONTA GROSSA/PR JULHO/2018

\author{
Ingrid Gayer Pessi - UNINTER - ingridgayerp@gmail.com \\ João Augusto Mattar Neto－ UNINTER - joaomattar@gmail.com
}

Tipo: Investigação Científica (IC)

Natureza: Relatório Final de Pesquisa

Categoria: Pesquisa e Avaliação

Setor Educacional: EDUCAÇÃO SUPERIOR

\begin{abstract}
RESUMO
O presente trabalho se configura como uma investigação científica de caráter bibliográfico e tem como objetivo refletir sobre papel do tutor no processo de aprendizagem de alunos da modalidade de Educação a Distância. A pesquisa não visa propor resultados a partir de investigações de campo, mas provocar reflexões acerca dessa modalidade. A metodologia é de caráter comparativo de obras teóricas que tratam do conceito e de visões sobre o papel do tutor. Foram selecionados 10 artigos para levantar insumos de análise e comparação. A fundamentação teórica sustentou-se a partir dos seguintes autores: Azevedo (2008), Pretti (1996), Salvador (2000), Silva (2008) e Sousa (2004). Chegou-se à conclusão de que a aprendizagem do aluno de educação a distância depende, entre outros fatores, do papel exercido pelo tutor nesse processo como mediador e facilitador do processo educativo.
\end{abstract}

Palavras-chave: Aprendizagem. Educação à Distância. Tutor. Tutoria. 


\section{Introdução}

Para Kenski (2007, p. 75), a educação a distância "pode ser entendida como uma educação que liberta os envolvidos na ação educativa das rígidas determinações dos espaços e tempos da educação escolar tradicional." Essa modalidade exige do aluno características básicas para o sucesso em seu processo de aprendizagem: autonomia, responsabilidade, organização, entre outros (ABRÃO et al, 2011).

Nesse sentido, o papel do tutor é fundamental, auxiliando o aluno e construindo uma relação de cooperação no ambiente virtual de aprendizagem.

\footnotetext{
Nesse processo de construção do conhecimento, que envolve diferentes atores e tem no tutor um personagem fundamental, é necessário entender a aprendizagem como pessoal, potencializada pelo grupo, com interferência da ação dos orientadores acadêmicos, visando a obter objetivos bem marcados e definidos. (AZEVEDO, 2008, $p$. 25).
}

Esta pesquisa se configura como uma investigação científica de caráter bibliográficocomparativo, com o objetivo de refletir sobre o papel do tutor no processo de aprendizagem de alunos da modalidade de educação a distância (EaD). A segunda seção do artigo apresenta a metodologia e um quadro teórico com pesquisas acerca do tema, que serviram de base para a terceira seção, que discute os delineamentos do papel do tutor em EaD, quando são incorporados alguns referenciais teóricos. Por fim, são apresentadas as conclusões.

\section{Metodologia}

Foi realizada uma busca no Google Acadêmico por pesquisas que apresentassem o papel ou as funções do tutor no processo de aprendizagem dos alunos de EaD. Para tal, foram utilizados os indexadores: "tutoria em EaD" e "tutoria" "EaD" para trabalhos publicados entre os anos de 2009 e 2018 em língua portuguesa. Para a seleção, foram descartadas dissertações, teses e citações, sendo realizada somente a avaliação de artigos publicados.

Para selecionar artigos que correspondessem ao objetivo deste trabalho, que é refletir sobre papel do tutor no processo de aprendizagem de alunos da modalidade de educação a distância, foi realizada uma leitura exploratória dos materiais, especificamente de seus resumos. Após essa análise inicial, foram selecionados e lidos integralmente os 10 primeiros artigos resultantes da busca que apresentavam contribuições, discussões e reflexões relevantes sobre a prática e o papel do tutor em EaD. Não se trata, portanto, de uma revisão sistemática de literatura, mas uma busca 
exploratória de algumas pesquisas na área.

O Quadro 1 apresenta a data de publicação, os autores, os títulos dos textos e um breve comentário sobre o papel do tutor em cada um dos artigos selecionados.

\section{Quadro 1 - Comparativo sobre a concepção do papel de tutor em EaD}

\begin{tabular}{|c|c|c|c|}
\hline Ano & Autor & Título do artigo & Papel do tutor \\
\hline 2016 & Eniel do Espirito Santo & $\begin{array}{c}\text { Ensinar e aprender na } \\
\text { Educação a Distância: } \\
\text { um estudo } \\
\text { exploratório na } \\
\text { perspectiva das } \\
\text { práticas tutoriais }\end{array}$ & $\begin{array}{l}\text { O tutor é aquele que tem o contato } \\
\text { direto com os alunos e, por esse } \\
\text { motivo, suas práticas exigem atenção, } \\
\text { visto que suas ações podem contribuir } \\
\text { para motivar os estudantes ou fazer } \\
\text { com que se sintam isolados e } \\
\text { desmotivados. }\end{array}$ \\
\hline 2015 & $\begin{array}{l}\text { Felipe Pacheco e } \\
\text { Paula Cristina Dias } \\
\text { Sardinha }\end{array}$ & $\begin{array}{c}\text { A importância do tutor } \\
\text { em ambientes de } \\
\text { ensino- } \\
\text {-aprendizagem e } \\
\text { ferramentas de } \\
\text { avaliação em } \\
E a D \\
\end{array}$ & $\begin{array}{l}\text { O tutor deve possuir um papel de } \\
\text { liderança entre os estudantes, } \\
\text { participando ativamente do processo } \\
\text { educacional, tornando o ambiente } \\
\text { virtual de aprendizagem dinâmico, } \\
\text { motivador e interativo. }\end{array}$ \\
\hline 2014 & $\begin{array}{l}\text { Elizete V. de Souto, } \\
\text { Thaís Tenório e } \\
\text { André Tenório }\end{array}$ & $\begin{array}{l}\text { Percepções sobre a } \\
\text { competência } \\
\text { socioafetiva de } \\
\text { cordialidade e a } \\
\text { humanização da } \\
\text { tutoria a distância }\end{array}$ & $\begin{array}{l}\text { É aquele que deve propor atividades } \\
\text { interativas e problematizadoras, } \\
\text { incentivando o diálogo entre os } \\
\text { cursistas e agindo de forma cordial, } \\
\text { envolvendo de forma significativa o } \\
\text { educando no processo de } \\
\text { aprendizagem. }\end{array}$ \\
\hline 2013 & $\begin{array}{c}\text { Vanessa Battestin } \\
\text { Nunes }\end{array}$ & $\begin{array}{c}\text { O papel do tutor na } \\
\text { Educação a Distância: } \\
\text { o estado da arte }\end{array}$ & $\begin{array}{c}\text { Sujeito que participa ativamente do } \\
\text { processo de aprendizagem, } \\
\text { acompanha, avalia e contribui, através } \\
\text { de sua prática, com o projeto } \\
\text { pedagógico do curso, bem como } \\
\text { promove espaços de construção } \\
\text { coletiva de conhecimentos. } \\
\end{array}$ \\
\hline 2013 & Alice Fogaça Monteiro, & Tutoria a distância: & O tutor deve fazer do ambiente $\mathrm{v}$ \\
\hline
\end{tabular}




\begin{tabular}{|c|c|c|c|}
\hline & $\begin{array}{l}\text { Ana Carolina Oliveira } \\
\text { Salgueiro de Moura e } \\
\text { Berenice Vahl Vaniel }\end{array}$ & afetiva e efetiva & $\begin{array}{c}\text { de aprendizagem um espaço } \\
\text { acolhedor, dividindo com os alunos a } \\
\text { responsabilidade em aprender com } \\
\text { eles, trocando experiências, } \\
\text { encurtando distâncias e propiciando ao } \\
\text { aluno uma aprendizagem afetiva e } \\
\text { efetiva. }\end{array}$ \\
\hline 2012 & $\begin{array}{l}\text { Juliana Cereda Dale } \\
\text { Vedove e Rosi } \\
\text { Teresinha Munaretti de } \\
\text { Camargo }\end{array}$ & $\begin{array}{c}\text { A influência da } \\
\text { empatia na relação } \\
\text { tutor-aluno }\end{array}$ & $\begin{array}{l}\text { Ao desempenhar bem suas funções, o } \\
\text { tutor possibilita ao aluno uma } \\
\text { aprendizagem facilitada e eficiente. } \\
\text { Nesse sentido, é necessário que } \\
\text { reconheça sua responsabilidade no } \\
\text { processo de ensino e aprendizagem, } \\
\text { reavaliando seu trabalho e buscando } \\
\text { novos conhecimentos. }\end{array}$ \\
\hline 2011 & $\begin{array}{c}\text { Denise Martins de Abreu } \\
\text { e Lima, Mario Nunes } \\
\text { Alves }\end{array}$ & $\begin{array}{c}\text { O feedback e sua } \\
\text { importância no } \\
\text { processo de tutoria a } \\
\text { distância }\end{array}$ & $\begin{array}{l}\text { O sucesso da implementação de uma } \\
\text { proposta de EaD em uma instituição } \\
\text { depende da boa formação da equipe } \\
\text { de tutores, por se tratar de uma tarefa } \\
\text { desafiadora e complexa. }\end{array}$ \\
\hline 2011 & $\begin{array}{c}\text { Herbert Soares } \\
\text { Bernardino }\end{array}$ & $\begin{array}{l}\text { A tutoria na EAD: os } \\
\qquad \text { papéis, as } \\
\text { competências e a } \\
\text { relevância do tutor }\end{array}$ & $\begin{array}{l}\text { O tutor é o protagonista da ação } \\
\text { educativa, fazendo o elo entre o aluno } \\
\text { e o professor, permitindo a construção } \\
\text { de saberes de maneira coletiva. }\end{array}$ \\
\hline 2010 & Rejane Leal Schlosser & $\begin{array}{c}\text { A atuação dos tutores } \\
\text { nos cursos de } \\
\text { educação a distância }\end{array}$ & $\begin{array}{l}\text { O tutor assume um papel de orientador } \\
\text { na aprendizagem do aluno, que, em } \\
\text { parceria, acompanha sua vida } \\
\text { acadêmica, buscando soluções para } \\
\text { determinados problemas em sua } \\
\text { aprendizagem. É o facilitador do } \\
\text { conhecimento, devendo estar integrado } \\
\text { e consciente dos conteúdos, das } \\
\text { metodologias e, principalmente, do } \\
\text { contexto em que o aluno está } \\
\text { inserindo, sua realidade, suas } \\
\text { limitações e seu potencial. } \\
\text { Os resultados positivos e negativos do } \\
\text { aluno de educação a distância também }\end{array}$ \\
\hline
\end{tabular}




\begin{tabular}{|c|c|c|c|} 
& & & $\begin{array}{c}\text { são resultados da participação do tutor } \\
\text { no seu processo de formação. }\end{array}$ \\
\hline $\begin{array}{c}\text { Margarida R. Tarouco e e } \\
\text { Patricia Alejandra Behar }\end{array}$ & $\begin{array}{c}\text { Competências: } \\
\text { desafios para alunos, } \\
\text { tutores e professores } \\
\text { da EaD }\end{array}$ & $\begin{array}{c}\text { Para que desenvolvam um bom } \\
\text { trabalho, tanto o tutor a distância } \\
\text { quanto o tutor presencial precisam ser } \\
\text { dinâmicos, críticos, capazes de } \\
\text { interagir com os alunos, ter domínio e } \\
\text { conhecimento das novas tecnologias } \\
\text { de informação e comunicação, além } \\
\text { das competências cognitivas, técnicas, } \\
\text { pedagógicas, comunicativas e de } \\
\text { suporte social. }\end{array}$ \\
\hline
\end{tabular}

Fonte: os próprios autores

Para a análise e discussão dos resultados da pesquisa, foram identificadas as categorias mais importantes nos textos que definiam o papel e as funções dos tutores em educação a distância, enriquecidas com o suporte de referencial teórico incorporado à seção seguinte.

\section{Análise do perfil do tutor em EaD}

As pesquisas indicadas no Quadro 1 apontam que o bom andamento das atividades a distância depende, em parte, da ação do tutor, que tem o papel de orientar e mediar o conhecimento de forma personalizada, auxiliando os alunos em suas necessidades educativas, considerando as possíveis dificuldades individuais.

Percebe-se que agindo como mediador da aprendizagem, o tutor atua como intérprete do curso em questão, esclarece dúvidas e, segundo Bernardino (2011) e Nunes (2013), estimula saberes de forma coletiva, incentiva conquistas e avalia a aprendizagem.

[...] o tutor respeitando a autonomia da aprendizagem de cada cursista, estará constantemente orientando, dirigindo e supervisionando o processo de ensino-aprendizagem [...]. É por intermédio dele, também, que se garantirá a efetivação do curso em todos os níveis. (PRETTI, 1996, p. 27).

Ainda conforme os trabalhos analisados, a tutoria consiste em olhar individualmente 0 aluno, não deixando de atender todo o contexto de aprendizagem. Outro aspecto considerado relevante é conhecer a realidade dos alunos: pessoal, profissional, social e familiar, ajudando a construir bases de confiança e motivação, favorecendo a aprendizagem e o diálogo (SCHLOSSER, 2010). Além de ser um facilitador, o tutor é 
capaz de compreender as dificuldades do aprendiz quando se torna um observador e conselheiro, refletindo e compreendendo a trajetória acadêmica e pessoal do aluno (SILVA, 2008).

As pesquisas apontam que, ao problematizar o conhecimento, o tutor promove a expansão dos conceitos elaborados pelos alunos, aproximando-os de novos conhecimentos e informações de maneira progressiva e reflexiva, impulsionando o aluno à curiosidade pelo desconhecido (SOUTO; TENÓRIO; TENÓRIO, 2014).

Entre os domínios do conhecimento do tutor, destacam-se: capacidade de resolver problemas, processar informações, responsabilidade, empatia, cooperação e interação, entre outros. Para Santo (2014) e Pacheco e Sardinha (2015), a motivação também apresenta um importante elemento na ação tutorial e exerce influência direta na aprendizagem.

O estudo da motivação em relação à aprendizagem escolar remete à tentativa de compreender o que serve de incentivo ao aluno para realizar tal aprendizagem - o que o 'move' a aprender - e como isso reflete em elementos como, por exemplo, o grau de aceitação ou negação das tarefas escolares e a maior ou menor tendência a perseverar na realização dessas tarefas. (SALVADOR, 2000, p. 99).

Nesse sentido, percebe-se que a motivação está diretamente ligada às metas de aprendizagem que o aluno pode estabelecer para a realização de suas atividades escolares.

Salvador (2000) ressalta ainda que, nas aulas em que o professor é eficaz e configura um ambiente de aprendizagem caracterizado mais pelos elogios e pela motivação positiva, é possível obter melhores resultados. Tal observação se faz emergente e válida na atuação do professor/tutor de educação a distância, pois o modo como dá feedback ao aluno pode tanto estimulá-lo na continuidade do curso, quanto na desistência.

Algumas ações são primordiais e necessárias para ser um tutor a distância. Entre elas, elencam-se:

Responder perguntas e dúvidas sobre conteúdo e metodologia de um programa, preparar bancos de respostas para perguntas mais frequentes, preparar esquemas de conteúdo para explicações solicitadas, providenciar respostas para perguntas e dúvidas sobre questões que tangenciam conteúdos de um programa, corrigir e devolver trabalhos realizados pelos alunos, selecionar trabalhos de alunos para envio aos participantes e utiliza-los nas atividades sugeridas, estimular os alunos a elaborarem um plano de estudo e de administração de tempo, provocar e estimular a participação com perguntas e desafios, acompanhar a realização das atividades pelo aluno, considerando em que momento se encontra em relação ao conjunto do programa e aos demais colegas, quando se trata de uma turma que progride em conjunto, ser a presença que minimiza a solidão do aprendiz manifestandose periodicamente para dialogar com o aluno, mesmo sem ter sido solicitado, verificar o que está acontecendo 
com aqueles que não se manifestam por um certo período, pois são os principais candidatos a abandonar 0 programa. (SOUSA, 2004, p. 2).

Ainda segundo Vedove e Camargo (2012) e Schlosser (2010), quando reconhece a importância do seu papel, o tutor torna-se o facilitador e mediador da aprendizagem, incentivando o aluno a buscar e construir seu próprio conhecimento, tornando-se ativo e autônomo no ambiente virtual.

Todos estes critérios devem ser considerados e somados à capacitação e formação profissional do professor/tutor em consonância com projeto político pedagógico dos cursos e com as disciplinas em que atua. A formação desse profissional ainda é vista, conforme Lima e Alves (2011), como tarefa desafiadora e complexa.

Porém, quando a metodologia e as novas tecnologias de informação e comunicação são aplicadas de forma adequada (KONRATH; TANROUCO; BEHAR, 2009), são capazes de levar tutor, aluno e colegas a fazerem parte de uma rede de interação, oportunizando o desenvolvimento de competências e habilidades pelas trocas de experiências.

Mesmo a pesquisa apresentando resultados de diferentes contextos e períodos, é possível observar um alinhamento naquilo que se espera do tutor a distância. Seu trabalho necessita de organização, planejamento e comprometimento com a aprendizagem dos alunos.

\section{Considerações finais}

A educação a distância é uma modalidade de ensino com metodologias próprias, que procuram evitar a passividade do aluno durante o processo de ensino, visando uma aprendizagem efetiva do aluno em ritmo próprio. Conhecer essas metodologias e dominar as mídias do curso em que o tutor atua são de fundamental importância para o exercício da função.

A tutoria compreende um conjunto de ações educativas que podem ser desenvolvidas a distância, com a capacidade de proporcionar uma ação educativa na busca constante da autonomia intelectual e no desenvolvimento do potencial dos alunos.

Por meio desta pesquisa, evidenciou-se que ao motivar, orientar e estimular a aprendizagem do aluno, o tutor abre perspectivas para debates, confrontos e discussões de diferentes pontos de vista, fazendo da diversidade uma possibilidade de reflexão sobre os mais diversos assuntos. 
Entre seus atributos, espera-se que o tutor busque promover a aprendizagem, minimizando as dificuldades encontradas pelos alunos no ambiente virtual, ao estabelecer uma relação colaborativa e empática. Ao estar ciente da importância do seu papel, o tutor encurta a distância entre o aluno e o conhecimento, bem como o aproxima de suas próprias potencialidades.

\section{Referências}

ABRÃO, Ruhena Kelber et al. A construção das identidades dos alunos de EaD através dos seus discursos em um fórum de discussão. Disponível em: <http://www.repositorio.furg.br/handle/1/1385>. Acesso em: 06 jul. 2018.

ABREU E LIMA, Denise Martins; ALVES, Mario Nunes. O feedback e sua importância no processo de tutoria a distância. Pro-Posições, v. 22, n. 2, p. 189-205, fev. 2016.

AZEVEDO, Adriana Barroso de. Tutoria em EAD para além dos elementos técnicos e pedagógicos. In: III Seminário EAD - Ufes - Formação de professores, tutores e coordenadores de polos para UAB. 22 a 24 set. 2008.

BERNARDINO, Herbert Soares. A tutoria na EaD: os papéis, as competências e a relevância do tutor. Revista Paidéi@, UNIMES VIRTUAL, v. 2, n. 4, 2011.

KENSKI, Vani Moreira. Educação e tecnologias. Campinas, SP: Papirus, 2007.

MONTEIRO, Alice Fogaça; MOURA, Ana Carolina Oliveira Salgueiro de; VANIEL, Berenice Vahl. Tutoria a distância: afetiva e efetiva. In: Tutor/autor: experiências e saberes, p. 11, 2013. Disponível em: <http://sabercom.furg.br/bitstream/1/1583/1/Tutorautor-experiencias-e-saberes.pdf\#page=11>. Acesso em: 16 maio 2018.

NUNES, Vanessa Battestin. O papel do tutor na educação a distância: o estado da arte. In: ESUD 2013 - X Congresso Brasileiro de Ensino Superior a Distância, 2013. Disponívelem:<http://cefor.ifes.edu.br/images/stories/Documentos_Institucionais/2013/1 14143_oral.pdf> Acesso em: 16 maio 2018.

PACHECO, Felipe; SARDINHA, Paula Cristina Dias. A importância do tutor em ambientes de ensino-aprendizagem e ferramentas de avaliação em EAD. Comunicação \& Mercado/UNIGRAN, v. 04, n. 10, p. 142-150, jul-dez 2015. Disponível em: <http://www.unigran.br/mercado/paginas/arquivos/edicoes/10/12.pdf>. Acesso em: 17 maio 2018. 
PRETTI, Oreste (Org.). Educação a distância: inícios e indícios de um percurso. Cuiabá: Universidade Federal do Mato Grosso, 1996.

SALVADOR, César C. et al. Psicologia do ensino. Trad. Cristina Maria de Oliveira. Porto Alegre: Artmed, 2000.

SANTO, Eniel do Espírito. Ensinar e aprender na Educação a Distância: um estudo exploratório na perspectiva das práticas tutoriais. Research, Society and Development, v. 3 , n. 2, p. 92-114, 2016. Disponível em: <https://dialnet.unirioja.es/servlet/articulo?codigo=6070040>. Acesso em: 17 maio 2018.

SILVA, Marinilson Barbosa. O processo de construção de identidades individuais e coletivas do ser-tutor no contexto da educação a distância, hoje. Tese (Doutorado em Educação), Universidade Federal do Rio Grande do Sul - UFRGS, Porto Alegre, 2008.

SOUSA, C. A. L. Fundamentos de educação a distância e sistema de tutoria. Apostila. Aula 4. Universidade Católica de Brasília, DF, 2004.

SOUTO, Elizete Ventura de; TENÓRIO, Thaís; TENÓRIO, André. Percepções sobre a competência socioafetiva de cordialidade e a humanização da tutoria a distância. Revista EaD em FOCO, v. 4, n. 1, abr. 2014. Disponível em: <http://eademfoco.cecierj.edu.br/index.php/Revista/article/view/199>. Acesso em: 16 maio 2018.

VEDOVE, Juliana Cereda Dale; CAMARGO, Rosi Teresinha Munaretti de. A influência da empatia na relação tutor-aluno. Revista Intersaberes, v. 3, n. 6, p. 155-165, 2012. Disponível em: <https://www.uninter.com/intersaberes/index.php/revista/article/view/135> Acesso em: 16 maio 2018. 